\title{
N1a Stage Finding
}

National Cancer Institute

\section{Source}

National Cancer Institute. N1a Stage Finding. NCI Thesaurus. Code C48707.

A general term that refers to a TNM finding of cancer metastases usually in a limited number of regional lymph nodes. The definition of N1a TNM finding depends on the specific type of cancer that it refers to; for example, for breast cancer it refers to metastasis in 1 to 3 axillary lymph nodes (at least 1 tumor deposit greater than $2.0 \mathrm{~mm}$ ); for cutaneous melanoma it refers to micrometastasis in one regional lymph node; for colorectal cancer it refers to metastasis in one regional lymph node. 